\title{
Building Bridges Through Understanding the Village Workshop: Transforming Nursing Students' Perspectives of Indigenous People and Canadian History - Atelier « Building Bridges Through Understanding the Village »: Transformer la vision qu'ont les étudiantes en sciences infirmières des peuples autochtones et de l'histoire du Canada
}

\author{
Donna E. Martin \\ University of Manitoba, donna.martin@umanitoba.ca \\ Kendra Rieger \\ University of Manitoba, kendra.rieger@umanitoba.ca
}

Suzanne Lennon

University of Manitoba, suzanne.lennon@umanitoba.ca

Rachel Mangiacotti

University of Manitoba, mangiacr@myumanitoba.ca

Kathi Camilleri

cckc@telus.net

Follow this and additional works at: https://qane-afi.casn.ca/journal

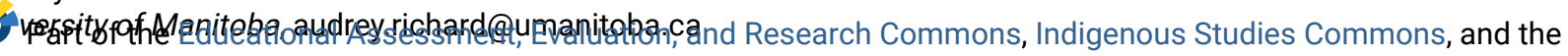
Dursing Commons

University of Mânituba, David.Düsolo@ummanitoba.ca

Recommended Citation

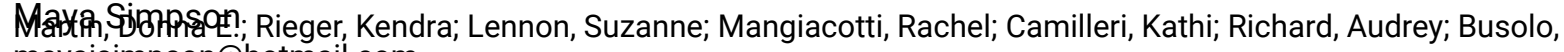

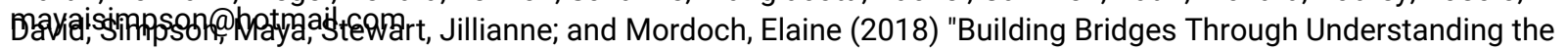
Village Workshop: Transforming Nursing Students' Perspectives of Indigenous People and Canadian History - Atelier «Beilding Bridges Through Understanding the Village » : Transformer la vision qu'ont les étudiantes en sciences infirmières des peuples autochtones et de l'histoire du Canada," Quality Advancement in Nursing Education Avancées en formation infirmière: Vol. 4: Iss. 2, Article 2.

DOI: https://doi.org/10.17483/2368-6669.1148

This Article is brought to you for free and open access by Quality Advancement in Nursing Education - Avancées en formation infirmière. It has been accepted for inclusion in Quality Advancement in Nursing Education - Avancées en formation infirmière by an authorized editor of Quality Advancement in Nursing Education - Avancées en formation infirmière. 


\section{Building Bridges Through Understanding the Village Workshop: Transforming Nursing Students' Perspectives of Indigenous People and Canadian History - Atelier « Building Bridges Through Understanding the Village » : Transformer la vision qu'ont les étudiantes en sciences infirmières des peuples autochtones et de l'histoire du Canada}

\section{Cover Page Footnote}

We acknowledge the College of Nursing Endowment Fund and Indigenous Achievement at the University of Manitoba for their support of the Building Bridges Through Understanding the Village. Nous remercions le Endowment Fund and Indigenous Achievement du College of Nursing de l'Université du Manitoba pour leur soutien à l'atelier « Building Bridges Through Understanding the Village ».

\section{Authors}

Donna E. Martin, Kendra Rieger, Suzanne Lennon, Rachel Mangiacotti, Kathi Camilleri, Audrey Richard, David Busolo, Maya Simpson, Jillianne Stewart, and Elaine Mordoch 


\section{Introduction}

In 2016, Kathi Camilleri offered the arts-based workshop Building Bridges Through Understanding the Village $^{\odot}$ to those interested in an interprofessional educational workshop focusing on the Indigenous perspective. During this experiential workshop, participants explore their personal role in supporting the revival of the values from Indigenous villages for thousands of years. They also explore the effects of Residential Schools and Canada's Policy of Assimilation. To evaluate the effectiveness of the workshop, a mixed methods design using a cross-sectional survey was used to describe participants' experiences of an experiential workshop. The Building Bridges workshops were held at a university located in Western Canada in 2016 with 213 attendees. The following paper is a discussion of the study and its results.

\section{Background}

In 2015, the Truth and Reconciliation Commission (TRC) called upon all levels of government to increase the number of health care professionals with Indigenous ancestry and provide education for all health care professionals in the realm of cultural safety. The TRC (2015) also issued a call for Canadian nursing schools to require all students to complete a course addressing Indigenous health issues. According to the TRC Calls to Action, the content should include the history and legacy of residential schools, treaties and Indigenous rights, Indigenous teachings and practices, skills-based training in intercultural competency, conflict resolution, human rights, and anti-racism (TRC, 2015). Echoing these priorities, registered nurse entry-level competencies include the application of knowledge of health disparities and inequities of Indigenous peoples in nursing practice (College of Registered Nurses of Manitoba, 2013). Innovative pedagogical strategies are needed to fulfil this obligation to current and future nursing students.

A challenge for nurse educators is to move beyond problematic and contested models of cultural awareness and cultural competence to provide transformative educational programs that generate nurses who promote health equity and social justice (Hart, Cavanagh, \& Douglas, 2015; Pauly, McCall, Browne, Parker, \& Mollison, 2015). While traditional learning activities may perpetuate cultural essentialism, experiential learning elicits a shared and multi-faceted experience within one's learning community (Mezirow, 2009). Addressing personal assumptions and biases through reflections on an active learning experience can challenge participants to embrace a more open, critical, and judicious perspective (Mezirow, 2009). Experiential artsbased learning activities are evidence-based strategies that enhance nursing students' selfawareness, empathy for others, and deeper understandings of barriers to health care (Rieger \& Chernomas, 2013; Rieger, Chernomas, McMillan, Morin, \& Demczuk, 2016; Yang, Woomer, Agbemenu, \& Williams, 2014). This foundational know-how-to-be promotes cultural safety in nursing practice. Table 1 provides definitions and steps in the process of developing culturally safe nursing practice.

Table 1

Components Leading to Cultural Safety and Cultural Humility

\begin{tabular}{cl}
\hline Component & Definition \\
\hline Cultural awareness & $\begin{array}{l}\text { The initial step to achieve cultural safety. It is the basic } \\
\text { acknowledgment that similarities and differences exist between }\end{array}$
\end{tabular}




\begin{tabular}{ll}
\hline & cultures, such as between the practitioner and the patient (Aboriginal \\
& Nurses Association of Canada [A.N.A.C.], 2009). \\
Cultural sensitivity & The second step to achieve cultural safety. The need to respect cultural \\
& differences is recognized, although this step does not require an \\
& individual to reflect upon their own culture (A.N.A.C., 2009; Baba, \\
& 2013). \\
Cultural competence & Fusing cultural awareness and cultural sensitivity, it is the application \\
& of the skills, knowledge and attitudes of practitioners to enhance cross- \\
& cultural communication (A.N.A.C., 2009; Darroch et al., 2017). This \\
& step involves the practitioner examining their own culture. \\
& The summation of elements from cultural awareness, sensitivity, and \\
& competence; the practitioner can communicate competently with a \\
patient in that patient's unique social, political, linguistic, economic \\
and spiritual realm (National Aboriginal Health Organization, 2008). It \\
is achieved through critical self-reflection and the analysis of power \\
imbalances, institutional discrimination, colonization, and colonial \\
relationships and their impact on health care (A.N.A.C., 2009; Lewis et \\
al., 2014). It also involves the practitioner taking on a health advocacy \\
role (University of Ottawa, 2017). \\
Involves redefining cultural competency into an ongoing process of \\
lifelong self-reflection and maintaining humility in patient-practitioner \\
relationships; it also implies the desire to mitigate power imbalances \\
between patient and practitioner (University of Ottawa, 2017).
\end{tabular}

Cultural safety has been proposed as an approach to disrupt the effects of stigma, discrimination, and marginalization within health care contexts (Pauly et al., 2015). Cultural safety was originally developed by Indigenous nursing students and scholars to facilitate more respectful care to Indigenous peoples in the New Zealand context (Pauly et al., 2015). In Canada, cultural safety has been identified as a "strategy for extending beyond cultural sensitivity and cultural competence, and focusing attention on power imbalances, institutional discrimination, and the inequitable positioning of certain groups within these dynamics" (Pauly et al., 2015, p. 122). In the Canadian context, cultural safety has deepened health care providers' understanding of the impact of historical trauma and systemic racism on Indigenous people's health status, access to health care and health care experiences (Pauly et al., 2015).

As opposed to linear traditional teaching strategies, arts-based pedagogy facilitates experiential learning (Rieger \& Chernomas, 2013; Rieger et al., 2016). The term "experiential learning" has been used interchangeably with simulation, role-play, and clinical placements (Fossen \& Stoeckel, 2016; Kidd, Tusaie, Morgan, Preebe, \& Garrett, 2015). One experiential learning strategy used in nursing has been "Hearing Voices Which Are Distressing", developed by Deegan in 2006. This experiential learning enhanced students' self-awareness, empathy, and ability to develop therapeutic relationships (Fossen \& Stoeckel, 2016; Kidd et al., 2015). In particular, the "Hearing Voices Which Are Distressing" simulation facilitated deeper understandings of people with mental illnesses and changed students' attitudes, values, and 
beliefs (Ward, 2015). In this experiential workshop, participants are briefed about the experience, listen to a special audio-recording that simulates distressing voices characteristic of those experienced by someone with a mental illness. Participants simultaneously perform mental, psychomotor, and social tasks. Educational and mental health organizations provide this workshop to increase understanding of the lived experience of mental illness and prepare students to support people in recovery from mental illness (Deegan, 2006).

Experiential learning has also enriched nursing students' attitudes towards people with addictions and special needs as well as people living in poverty (Norman, 2001; Vliem, 2015; Yang et al. 2014). In Australia, nurse educators concluded that experiential learning, role playing, and clinical placements improved students' awareness of the social determinants of health and fostered transformative learning with respect to Indigenous peoples' health and cultures (Allen, Brown, Duff, Nesbitt, \& Hepner, 2013; Hart et al., 2015; Townsend, Gray, \& Forber, 2016).

Informed by Indigenous epistemology, cultural safety, and Kolb's experiential learning theory, a student-led team comprised of undergraduates, graduates, and faculty members planned, implemented, and evaluated an arts-based experiential workshop (Allen et al., 2013). The arts-based workshop (Building Bridges Through Understanding the Village ${ }^{\odot}$ ) was facilitated by Kathi Camilleri, who self-identifies as having Aboriginal and Irish ancestry. A detailed description of her work can be found online at https://hollyhock.ca/programinfo/camilleri/ and is detailed in Table 2. Arts-based approaches are congruent with Indigenous peoples' values as it is a holistic approach to education (Patteson, Restoule, Margolin, \& Conely de Leon, 2010). In this half-day workshop, Camilleri led participants through an exploration of Indigenous peoples' history and encouraged them to discuss strategies to promote decolonization. Workshop participants explored the micro- and macro-construction of colonization and assimilation of Indigenous peoples. Participants were invited to assume various roles within an Indigenous community and took an interactive role-playing journey through time, experiencing life as an Indigenous person during pre-contact, European contact, assimilation, and to present-day Canada. Following this exploratory process in which the participants imagined themselves in the place of another, participants are provided with an opportunity to gain a clearer understanding of the effects of colonization and the impact of historical trauma. This deeper understanding may influence their future professional practice. Camilleri re-enacted history through a nonjudgmental/non-shameful lens. The workshop elicited cognitive and emotional responses as participants built their village and experienced it being taken away. Although it appeared that this event fostered transformative and meaningful learning about Indigenous peoples' history, without further investigation this important learning could remain unexplained and "anecdotal at best" (Diekelmann \& Ironside, 2002, p. 379). Thus, the purpose of this evaluative study was to describe participants' perspectives of the workshop and its impact on their learning to inform future educational initiatives.

Table 2

Outline of the Building Bridges Through Understanding the Village Workshop

Welcome and introductions
Participants arrived and formed a large circle around the facilitator. An Indigenous Elder opened the workshop with a prayer and the traditional territories of all local Indigenous groups were acknowledged. In the opening circle, participants' safety was 
Pre-European contact

European contact

Present day

Reflection on paths to healing and reconciliation

Closing intentionally built. The facilitator explained that in this workshop, no blame or shame was intended. Informed consent for the workshop was also discussed. The facilitator offered participants the choice in their level of participation and participants were asked to attend to self-care after the workshop.

Volunteers were invited to assume the role of children, parents, grandparents, and elders in an Indigenous village. They sat in an inner circle and artefacts were provided to enact relationships and imagine cultural practices. The facilitator reviewed key Indigenous values as they participated in the role-play.

The facilitator assumed the role of the colonizer, symbolized by wearing a red hat. Through role-play, participants experienced a theatrical simulation of the process of colonization including elements such as land appropriation, suppression of Indigenous culture, removal of children to residential schools, and assimilation.

Participants enacted the impact of colonization through the breaking of the circle, symbolized by participants standing in lines against the wall while the "red hat" colonizer interacted with the group in an oppressive manner.

Participants were asked to reflect first as members of an Indigenous community and then as health care professionals, regarding individual and societal actions towards reconciliation.

The facilitator led a sharing circle in which participants reflected on their new learnings and developed an intention for action. In closing, the facilitator and participants entered into a pact regarding acts of self-kindness after the emotionally intense workshop.

\section{Guiding Framework}

The workshop and evaluative study were guided by experiential learning theory (ELT) (Kolb, 1984). ELT is a pedagogical perspective that views learning as a transformation of experience that occurs through four phases: immersion in a concrete experience, reflective observation of that experience, formation of abstract conceptualizations, and active experimentation with new knowledge. According to this theory (Kolb, 1984), immersion in a concrete arts-based learning experience along with reflection on that experience forms new understandings. Participants then have the potential to move beyond cognitive recognition of historical events towards a deep emotional connection, which may inspire them towards action. The experiential workshop was implemented to foster meaningful pedagogical experiences in which learners could integrate new ideas about Canada's history with Indigenous people. ELT provided a theoretical rationale for this experiential and reflective arts-based workshop; it also informed the development of the study design and provided a lens for the data analysis. 


\section{Conducting the Workshop}

When preparing to conduct the "Building Bridges" workshop, it was vital to consider several factors. Camilleri's work was informed by consultations with Elders, and we suggest that educational administrators and nurse educators follow a similar consultation process with local Elders. The purpose of these consultations is to determine appropriate pedagogical approaches in teaching nursing students about the history and impact of residential schools as well as to cocreate ways to move forward with the TRC's Calls to Actions (2015). We believe in the importance of this information being imparted by Indigenous peoples whenever possible.

The workshop has the potential to evoke strong emotions of participants; while this is not an undesirable outcome, measures must be taken to ensure that participants feel emotionally safe and cared for. The following steps in Table 3 list a safety plan for participants.

Table 3

Building Bridges Through Understanding the Village Workshop - Safety Plan

Building Bridges Through Understanding the Village Workshop: Safety Plan

1 Participants are informed in advance of the subject matter and nature of the experiential training using a pre-course information package.

2 Participants are asked if they have a wellness plan and if they are able to access good selfcare should they need this following the workshop experience.

3 When the workshop begins, the workshop process is described in detail so that participants are informed about the level of experience and subject matter to be covered.

4 Participants are encouraged not to stay for the parts of the workshop that they feel might be difficult for them based on their life experience.

5 An integral part of the training is to ask participants to "buddy-up" (i.e., participate with partners or "buddies") and to commit to a self-care plan following the workshop. They are reminded to follow through with a self-care plan several times throughout the workshop. They are given the opportunity to debrief with their buddies and another buddy group in order to build supportive relationships with other participants.

6 Workshop participants are asked to think of and commit to three self-care activities that they will do the evening after the workshop that does not involve self-medicating.

7 A mental health clinician attends each workshop to provide support. After-workshop support is also available and offered by a facilitator. When a clinician or support person is not available, participants work with partners, and they are asked to support one another. A 24-hour support line (Indian Residential School Survivors Society) phone number is given to all participants.

8 Facilitator creates a safe circle, that is, a container filled with kindness and loving respect throughout the workshop. This safety supports healthy participation and maximum benefit to the participant. 


\section{Methods}

This study utilized a mixed methods design with a cross-sectional survey. This study was approved by the institution's research ethics board.

\section{Setting and Sample}

The study was conducted in a mid-Western Canadian university. The university offers a four-year undergraduate nursing program and a graduate nursing program. A convenience sample of undergraduate students, graduate students, faculty, and staff from the university who attended the workshop were invited to participate in the evaluative study. Students in the fourth year of the undergraduate nursing program were required to attend the workshop as it was linked to a course assignment. All other attendees participated on their own accord. Participants were invited to complete the evaluation form at the end of the workshop.

\section{Data Collection}

Data was collected using the researcher-developed Building Bridges Workshop Evaluation Questionnaire, which included a short demographic survey, a brief quantitative survey, and six open-ended questions. Several faculty, graduate students, and undergraduates were asked to review the evaluation tool for clarity and readability. The demographic survey collected information on the participant's role (student, staff, or faculty, etc.), age, and gender. Indigenous participants were not specifically identified as a sub-group.

The quantitative survey consisted of a five-item Likert scale anchored with $1=$ strongly disagree and 5=strongly agree. Possible scale scores ranged from 5-25 with higher scores indicating greater levels of satisfaction. The five declarative statements were designed to elicit participants' cognitive and emotional responses to the workshop as well as the usefulness of the workshop for current and future practice (see Table 4). Study participants completed the surveys with narrative responses to six open-ended questions regarding their motivations to participate, the impact of the workshop, and what aspects were most and least valuable. The final question asked for suggestions for improvement. During the last 15 minutes of each of the five workshops, participants signed an informed consent and were invited to complete the Building Bridges Workshop Evaluation Questionnaire.

\section{Data Analysis}

Narrative responses to the open-ended questions were transcribed verbatim into a Word document and analyzed using content analysis for significant statements and themes in order to describe attendees' perceptions of the workshop and its impact on their learning (Graneheim \& Lundman, 2004). We conducted line-by-line coding and then clustered codes into three main categories and one over-arching theme.

Quantitative data were entered into IBM SPSS Statistics for Windows, Version 24.0 (2016) and analyzed with descriptive and inferential statistics. The quantitative analysis occurred in several steps. In the first step, descriptive statistics of the sample including the role of the participant, gender, and age were examined. Average scores for each scale item were calculated. Next, we summed the scale, and a reliability analysis was conducted, generating a Cronbach's alpha. Then, we compared the average scores between undergraduates and graduate/faculty/staff and male and female participants. Since the group sizes were unequal and the distribution violated the assumption of normality, the Mann-Whitney U test was utilized. Lastly, we 
examined the association between age and scale scores. Since the distributions were non-normal, the Spearman's Rank Correlation Coefficient was used.

\section{Results}

\section{Sample Characteristics}

The workshop was attended by a total of 213 participants. Of these, 159 participants agreed to participate in the evaluation of the workshop, representing a response rate of $74.6 \%$. The majority of participants were fourth year undergraduate nursing students $(n=99,62.3 \%)$. Students (undergraduate and graduate) comprised $91.2 \%$ of the study participants, and the majority of the participants were female $(n=144,90.6 \%)$. There was a wide range of ages; the youngest participant was 19 years old, and the oldest was 61 years old. The mean age of participants was 26.8 years, and the mode for age was 22 years. Table 3 presents the characteristics of the sample. Some participants indicated their Indigenous ancestry in the narrative comments. Indigenous participants were not specifically identified as a sub-group in the demographic survey as the intention of this initial exploratory evaluative study was not to compare or contrast perspectives between Indigenous and non-Indigenous groups of participants.

Table 3

Characteristics of the Sample $(N=159)$

\begin{tabular}{lcc}
\hline Characteristic & $\mathrm{N}$ & $\%$ \\
\hline \multicolumn{1}{c}{ Role } & & \\
\hline 2nd year nursing student & 20 & 12.6 \\
3rd year nursing student & 19 & 11.9 \\
4th year nursing student & 99 & 62.3 \\
Graduate student & 7 & 4.4 \\
Staff member & 2 & 1.3 \\
Faculty member & 9 & 5.7 \\
Unknown & 3 & 1.8
\end{tabular}

Gender

\begin{tabular}{lcc}
\hline Female & 144 & 90.6 \\
Male & 14 & 8.8 \\
Unknown & 1 & 0.6
\end{tabular}

\section{Qualitative Findings: "Words can only do so much"}

Participants provided responses to open-ended questions from the survey. The overarching theme was "Words can only do so much," which was a statement provided by one participant. This statement symbolized the shared experiences of faculty, staff, and students. The 
participant reflected: "I like the role-play aspect of this workshop as words can only do so much. It allows us to not only participate, but provides an opportunity to experience it for ourselves." This overarching theme encapsulated three categories: 1) Imaginative empathy, 2) Made me feel made me think, and 3) Moving towards reconciliation.

Imaginative empathy. Participants described how role-playing during the experiential workshop helped them to imagine what it would be like to be a member of an Indigenous community throughout various stages of history. By symbolically building a village with cultural artifacts and incorporating love, respect, kindness, and generosity as the core values of their community, participants were able to reflect and identify with Indigenous community members' pre-contact, contact, and present-day experiences. One participant shared that they were especially moved by the forceful removal of the children, which was observed to reverberate in traumatic waves throughout the entire community. A nursing student expressed, "When the children were taken and the Indigenous peoples social setting was condemned and taken away, I pictured in my mind that the community became a graveyard." This imaginative response led to a deeper understanding that fostered crossing over into another's thoughts and feelings. This participant further expounded that the workshop "took me back in time and I was visualizing the community, the humiliation, disrespect the people were subjected to."

For many of the participants, the role-playing allowed them to develop a greater sense of empathy towards the experiences of Indigenous peoples. One participant shared how this imaginative process resulted in empathy: "I felt an emotional connection and just a lot of empathy. It's like a light suddenly switched on, and I realized this is such a serious issue today." Another participant identified that the most valuable aspect of the workshop was, "understanding their reality by being placed in their shoes," which made her "empathetic to the Aboriginal people and the reality of the way things are now."

Made me feel made me think. This workshop was found to address both cognitive and affective domains of learning and often integrated thinking and feeling within the same learning experience. Participants shared how cognitive and affective responses were inseparable and potentiated their synergistic learning. One student highlighted how the workshop "facilitated deeper understanding, appreciation of Indigenous culture and experiences through emotional and cognitive connection." Linking historical facts with actual emotions catalyzed deeper understandings of topics for which words alone are inadequate. A student revealed: "I can't even put it into words. It gave me a sense of the loss and trauma that colonization and residential schools has caused." The affective component seemed especially valuable and unique to some participants. A student identified how the role-playing "brought a level of emotional connection you really can't get in traditional classes." As several participants articulated the integration of cognitive and affective responses, the category "Made me feel made me think" is presented without punctuation separating the two concepts to illustrate their fluidity and interconnectedness. As one student succinctly stated, "it really made me feel a lot."

Moving towards reconciliation. Moving towards reconciliation was acknowledged to start with oneself, as one student noted: "the healing starts from within." Participants described deep reflections regarding personal beliefs that challenged preconceived notions. Not only did they imagine themselves as Indigenous people, but some participants also described how they saw a darker side of themselves in the colonizer. One student described that this revelation brought a "Greater awareness of the red hat (the colonizer), and that I may wear one at times, even if I do not think I am." 
This personal reflection on the workshop experience inspired a desire for action. One student shared that the most valuable aspect of the workshop was "knowing that I can make a difference as an advocate. It's really different when I am put in their shoes." Most participants became hopeful about their future role in the path towards healing, and one student recognized "My every little action as a nurse directed towards equity counts." In particular, nursing students described how they would incorporate what they learned in the workshop into their future nursing practice: "It helped me understand where my future patients may have come from so I can care for them medically and spiritually."

The experiential workshop broadened participants' perspectives of the social structures and systemic factors that shape Indigenous peoples' health and well-being. The workshop offered an opportunity "to stop and think about relationships between Indigenous people, the government and the Canadian people in general." Participants recognized the complexities within the process of reconciliation: "Healing takes time, and there is no one way for every person." Many participants began to acknowledge the wisdom and strength of Indigenous knowledge to guide the path towards reconciliation. This acknowledgement is illustrated in the following quote: "our world would be a much better place if we adopted the values of a traditional Aboriginal village: love, kindness, respect, generosity." Furthermore, some participants were able to link collaboration within an Indigenous village to collaboration within a nation, and one participant suggested the following: "we must come together and put aside our guilt and anger if we are to overcome our current issues and build a better Canada for all people." Participants shared that they were awestruck by the strength and resilience of Indigenous peoples, and they wanted to incorporate the values of the Indigenous village into their personal and professional lives.

\section{Quantitative Results}

Overall, the workshop was positively reviewed and highly rated by students and faculty. Data were missing for less than $3.0 \%$ of the participants, and questions with missing data were analyzed according to the number of completed questions. In terms of cognitive understanding, two questions explored this learning domain. Most participants indicated strong agreement that the workshop helped to better understand issues facing Indigenous groups $(n=113,71.1 \%)$ and that the workshop improved cognitive understanding regarding the impact of history on Indigenous peoples $(n=116,73.0 \%)$. Participants strongly endorsed the impact of the workshop on their emotional connections to the topic and on their future practice. Please see Table 4 for individual item results.

The average total scale scores were high $(\bar{x}=22.87, \mathrm{SD}=3.78)$. Cronbach's alpha for the five-item questionnaire was 0.96 , indicating excellent internal reliability consistency (Polit \& Beck, 2017). There were no significant differences between the average scale scores of men and women or between participants with different roles. Furthermore, no association was found between the ages of participants and total scale scores. Notably, there was no significant difference between fourth-year students who were required to attend and the remainder of the participants. The descriptive and inferential statistics demonstrate that the workshop was highly rated by a diverse set of participants. 


\section{Table 4}

Participants' Perspectives on the Workshop entitled Building Bridges through Understanding the Village $(N=159)$

\begin{tabular}{|c|c|c|c|c|c|c|}
\hline & $\begin{array}{c}\text { Strongly } \\
\text { Disagree } \\
\mathrm{n}(\%)\end{array}$ & $\begin{array}{c}\text { Disagree } \\
\mathrm{n}(\%)\end{array}$ & $\begin{array}{c}\text { Neutral } \\
\mathrm{n}(\%)\end{array}$ & $\begin{array}{l}\text { Agree } \\
\mathrm{n}(\%)\end{array}$ & $\begin{array}{l}\text { Strongly } \\
\text { Agree } \\
\text { n }(\%)\end{array}$ & $\begin{array}{l}\text { Score } \\
\bar{x} \text { (SD) }\end{array}$ \\
\hline $\begin{array}{l}\text { The workshop was } \\
\text { useful to me as a } \\
\text { student/faculty } \\
\text { member. }\end{array}$ & $6(3.8 \%)$ & $0(0 \%)$ & $3(1.9 \%)$ & $\begin{array}{c}42 \\
(26.4 \%)\end{array}$ & $\begin{array}{c}108 \\
(69.9 \%)\end{array}$ & $\begin{array}{l}4.55 \\
(.86)\end{array}$ \\
\hline $\begin{array}{l}\text { The workshop will help } \\
\text { me better understand } \\
\text { health and social issues } \\
\text { facing Indigenous } \\
\text { groups. }\end{array}$ & $6(3.8 \%)$ & $0(0 \%)$ & $3(1.9 \%)$ & $\begin{array}{c}37 \\
(23.3 \%)\end{array}$ & $\begin{array}{c}113 \\
(71.1 \%)\end{array}$ & $\begin{array}{l}4.58 \\
(.86)\end{array}$ \\
\hline $\begin{array}{l}\text { Experiential learning } \\
\text { facilitated a cognitive } \\
\text { understanding about } \\
\text { how history has } \\
\text { impacted Indigenous } \\
\text { peoples. }\end{array}$ & $5(3.1 \%)$ & $0(0 \%)$ & $1(0.6 \%)$ & $\begin{array}{c}36 \\
(22.8 \%)\end{array}$ & $\begin{array}{c}116 \\
(73.0 \%)\end{array}$ & $\begin{array}{l}4.63 \\
(.79)\end{array}$ \\
\hline $\begin{array}{l}\text { I experienced an } \\
\text { emotional connection } \\
\text { to Indigenous peoples' } \\
\text { experiences across } \\
\text { time. }\end{array}$ & $5(3.1 \%)$ & $0(0 \%)$ & $4(2.5 \%)$ & $\begin{array}{c}50 \\
(31.4 \%)\end{array}$ & $\begin{array}{c}99 \\
(62.3 \%)\end{array}$ & $\begin{array}{l}4.51 \\
(.83)\end{array}$ \\
\hline $\begin{array}{l}\text { The workshop will be } \\
\text { useful in my future } \\
\text { nursing practice. }\end{array}$ & $5(3.1 \%)$ & $0(0 \%)$ & $5(3.1 \%)$ & $\begin{array}{c}42 \\
(26.4 \%)\end{array}$ & $\begin{array}{c}104 \\
(65.4 \%)\end{array}$ & $\begin{array}{l}4.54 \\
(.84)\end{array}$ \\
\hline
\end{tabular}

\section{Discussion}

Nursing educators are increasingly embracing the arts to elicit transformative learning regarding complex ideas such as cultural safety, which is a highly nuanced and multi-faceted concept. Through understanding the history of an Indigenous village, the arts facilitated empathy in order to bridge cultural differences (Rieger \& Chernomas, 2013). As Bryant et al. (2003) argue, the emotional connection gained through role-playing engaged the learner and fostered motivation to change behaviours. Emotions were a key component of participants' experiences, and the resultant connection with others deepened understandings. Some participants were noticeably moved, and some were even tearful. These deep emotions can be unsettling to educators, and one must wrestle to understand the meaning behind the tears and determine whether they are helpful or hurtful. These strong emotions may be evidence of the student's 
deeper understanding of the grievous material with which they are presented. Consultation with Elders and the establishment of a safety plan-which was detailed in the section on conducting the workshop-can assist participants who are struggling with strong emotions during or following the workshop.

Previous research has demonstrated the utility of the arts in teaching complex and potentially distressing content, such as the destruction of Indigenous culture. Newcomb, Cagle, and Walker (2006) found that through reading imaginative literature, nursing students learned to accept patients with different cultural practices. Begoray and Banister (2008) describe how the use of reading circles helped students learn about Indigenous contexts. In a qualitative study exploring student learning in a psychosocial class infused with the arts, researchers found that the arts fostered students' cultural awareness (Jensen \& Curtis, 2008). Aranda, de Goeas, Davies, Radcliffe, and Christoforou (2015) used photography as a participatory tool to cultivate nursing students' critical understanding of culture and diversity in mental health nursing. However, no studies have yet investigated the use of the arts to foster comprehension of the residential school experience and its impact on multiple generations. To our knowledge, this is the first nursing study to explore the impact of an arts-based initiative to address the TRC's Calls to Action (2015).

The findings of this study support the assertions of ELT, which posit that meaningful learning occurs through personal experience, reflection on those experiences, and integration of the new knowledge. The role-playing aspect of this workshop engaged attendees in a novel learning activity, which allowed for an iterative cycle of experience (role-playing) and reflection (group discussion and narrative responses). Kolb (1984) writes that ELT offers a philosophically different view of the learning process than traditional educational methods; we found that this cyclic form of learning permitted a more meaningful and transformative understanding. ELT emphasizes the central role of experience in the learning process, which differentiates it from learning theories that downplay the role of subjective experience (Kolb, 1984). By inviting participants to assume the roles of Indigenous peoples throughout history and to feel what they might feel, deep insights were elicited at both a cognitive and emotional level. Kolb (1984) writes that ELT is "a holistic integrative perspective on learning that combines experience, perception, cognition, and behaviour” (p. 21).

As previously stated, almost two-thirds $(62.7 \%)$ of the participants were required to attend the workshop. Although many of the students who were required to attend had initially low expectations for the utility of the workshop, once completed, their perspectives were much different. As reflected in the narrative comments, students felt that they greatly benefited, and some even stated that it was one of the best learning experiences of their nursing education; they also stated that this workshop should be required for all nursing students. These findings suggest that the mandatory nature of the courses required by the TRC (2015) will not diminish their effectiveness if they are able to engage students.

\section{Strengths and Limitations}

As is the case with any study, this work has both strengths and limitations. One of the major strengths of this evaluation is that the workshop being examined is structured, evidencebased, and has a degree of fidelity. Thus, higher degrees of reliability could be obtained if the workshop evaluations were to be repeated. To the best of our knowledge, this study is the first of its kind to examine the impact of using an arts-based approach to address the TRC's Calls to 
Action (2015). We engaged participants with different roles (e.g., students, faculty, staff), and our findings demonstrate meaningful learning experiences across the board. Although the majority of this sample was comprised of undergraduate nursing students, there was a wide age range.

Limitations of the study include the cross-sectional nature of the design. Cross-sectional studies involve a "snapshot" of a phenomenon, and do not permit the assessment of the degree to which attitudes may change or develop over time. In the case of a reflective exercise such as Building Bridges, the participants continue to process the experiences long after the workshop has ended. This study does not reflect this evolution of feelings and perspectives. We are also unable to assess the impact of the workshop on participants' behaviours, which is an important issue in a practice discipline such as nursing. The study was conducted at only one site, limiting our evaluation to a specific population. We also have no data from non-responders, and these individuals may have had very different perspectives from those who did respond. There are also limitations inherent in the method used to conduct the evaluation. Participants provided narrative, written responses where, unlike in an interview or focus group setting, there is no opportunity to probe or clarify responses. Many of these limitations could be addressed in future studies.

\section{Future Research}

Future research studies regarding the workshop should be conducted across multiple sites. In this manner, the perspectives of a more diverse population of health care providers, students, and educators can be attained. It would also then be possible to compare how these different groups processed the experience. Future researchers could also make use of interviews and focus groups as a data collection method, and include Indigenous students' perspectives of the workshop, since this would allow participants to provide a richer, more in-depth assessment of how they felt the workshop impacted them and how it may influence their practice in the future. To gain the best sense of the impact that the workshop may have on the practice of health care professionals, we must look to the recipients of that care. In a potential future project, researchers could interview Indigenous clients who have received care from workshop attendees; using this information, the project could provide valuable insights into actual behaviour change. Furthermore, a future mixed-methods study is needed to investigate the impact of the workshop on future nursing practice.

\section{Conclusion}

A mixed methods design using a cross-sectional survey was used to describe participants' experiences of an experiential workshop entitled Building Bridges Through Understanding the Village. The quantitative results and qualitative findings support the evidence that meaningful learning occurs through personal experience, reflection on those experiences, and integration of the new knowledge. The role-playing aspect of this workshop engaged attendees in a novel learning activity and facilitated an iterative cycle of experience (role-playing) and reflection (group discussion and narrative responses). By inviting participants to assume the roles of Indigenous peoples throughout history and feel what they might feel, deep insights were elicited at both a cognitive and emotional level. This workshop is one of many strategies to ensure that the TRC Calls to Action (2015) are honoured. In this evaluative study, the majority of participants were nursing students. These participants identified that the workshop helped them to better understand the history and legacy of residential schools, treaties and Indigenous rights, 
and Indigenous teachings and practices. Workshop participants were encouraged to incorporate Indigenous values into their personal and professional lives (TRC, 2015). Further research is needed to explore the impact of other educational strategies to adequately prepare nursing students for entry-level competencies in the provision of culturally safe care. 


\section{References}

Aboriginal Nurses Association of Canada [A.N.A.C.]. (2009). Cultural competence and cultural safety in nursing education: A framework for First Nations, Inuit and Metis nursing. Ottawa, ON: Author.

Allen, J., Brown, L., Duff, C., Nesbitt, P., \& Hepner, A. (2013). Development and evaluation of a teaching and learning approach in cross-cultural care and antidiscrimination in university nursing students. Nurse Education Today, 33(12), 1592-1598. https://doi.org/10.1016/j.nedt.2012.12.006

Aranda, K., Goeas, S., Davies, S., Radcliffe, M., \& Christoforou, A. (2015). Let's go outside: Using photography to explore values and culture in mental health nursing. Journal of Psychiatric Mental Health Nursing, 22(5), 306-315. https://doi.org/10.1111/jpm.12201

Baba, L. (2013). Cultural safety in First Nations, Inuit and Metis public health: Environmental scan of cultural competency and safety in education, training and health services. Prince George, BC: National Collaborating Centre for Aboriginal Health. Retrieved from https://www.ccnsa-nccah.ca/docs/emerging/RPT-CulturalSafetyPublicHealth-BabaEN.pdf

Begoray, D., \& Banister, E. (2008). Learning about Aboriginal contexts: The reading circle approach. Journal of Nursing Education, 47(7), 324-326. https://doi.org/10.3928/01484834-20080701-01

Bryant, C., Coffman, L., Halas, J., Harris, R., Janzen, A., Morin, F., ...Walters, J. (2003). The arts in education. Retrieved from http://www.edu.gov.mb.ca/k12/cur/arts/draft_statement.pdf

College of Registered Nurses of Manitoba. (2013). Entry-level competencies for registered nurses: nursing practice expectations. Retrieved from https://www.crnm.mb.ca/uploads/document/document_file_92.pdf?t=1438266411

Darroch, F., Giles, A., Sanderson, P., Brooks-Cleator, L., Schwartz, A., Joseph, D., \& Nosker, R. (2017). The United States does CAIR about cultural safety: Examining cultural safety within Indigenous health contexts in Canada and the United States. Journal of Transcultural Nursing, 28(3), 269-277. https://doi.org/10.1177/1043659616634170

Deegan, P. (2006). Hearing voices curriculum: Complete training and curriculum package. Retrieved from https://www.patdeegan.com/

Diekelmann, N., \& Ironside, P. M. (2002). Developing a science of nursing education: innovation with research. Journal of Nursing Education, 41(9), 379.

Fossen, P., \& Stoeckel, P. R. (2016). Nursing students' perceptions of a hearing voices simulation and role-play: preparation for mental health clinical practice. Journal of Nursing Education, 55(4), 203-208. https://doi.org/10.3928/01484834-20160316-04

Graneheim, U. H., \& Lundman, B. (2004). Qualitative content analysis in nursing research: concepts, procedures and measures to achieve trustworthiness. Nurse Education Today 24(2), 105-112. https://doi.org/10.1016/j.nedt.2003.10.001

Hart, B., Cavanagh, M., \& Douglas, D. (2015). The "strengthening nursing culture project" - an exploratory evaluation study of nursing students' placements within Aboriginal medical 
services, Contemporary Nurse, 51(2-3), 245-256.

https://doi.org/10.1080/10376178.2016.1150190

Hollyhock. (2018). Indigenous wisdom: Welcome home to your village, June 4-8, 2018. https://hollyhock.ca/programinfo/camilleri/

Jensen, A. \& Curtis, M. (2008). A descriptive qualitative study of student learning in a psychosocial nursing class infused with art, literature, music, and film. International Journal of Nursing Education Scholarship, 5(1), 1-9. https://doi.org/10.2202/1548923x.1344

Kidd, L., Tusaie, K. R., Morgan, K. I., Preebe, L., \& Garrett, M. (2015). Mindful teaching practice: lessons learned through a hearing voices simulation. Issues in Mental Health Nursing, 36(2), 112-117. https://doi.org/10.3109/01612840.2014.953278

Kolb, D. A. (1984). Experiential learning: Experience as the source of learning and development. Upper Saddle River, NJ: Prentice-Hall Inc.

Lewis, S. L., Bucher, L., Heitkemper, M. M., Camera, I., Barry, M. A., Goodridge, D., \& Goldsworthy, S. (2014). Medical-surgical nursing in Canada: Assessment and management of clinical problems (3rd ed.). Toronto, ON: Elsevier.

Mezirow, J. (2009). An overview on transformative learning. In K. Illeris (Ed.), Contemporary theories of learning: Learning theorists...in their own words (pp. 90-105). New York, NY: Routledge.

National Aboriginal Health Organization. (2008). Cultural competency and safety: A guide for health care administrators, providers and educators. Ottawa, ON: Author.

Newcomb, P., Cagle, C., \& Walker, C. (2006). Using imaginative literature to foster cultural sensitivity. International Journal of Nursing Education Scholarship, 3(1). https://doi.org/10.2202/1548-923X.1194

Patteson, A., Restoule, J., Margolin, I., \& Conely de Leon, M. (2010). Arts-based teaching and learning as an alternative approach for Aboriginal learners and their teachers. Retrieved from http://www.ccl-cca.ca

Pauly, B., McCall, J., Browne, A., Parker, J., \& Mollison, A. (2015). Toward cultural safety Nurse and patient perceptions of illicit substance abuse in a hospitalized setting. Advances in Nursing Science, 38(2), 121-135. https://doi.org/10.1097/ans.0000000000000070

Polit, D., \& Beck, C. (2017). Nursing research: generating and assessing evidence for nursing practice. Philadelphia, PA: Wolters Kluwer Health.

Rieger, K. \& Chernomas, W. (2013). Arts-based learning: Analysis of the concept for nursing education. International Journal of Nursing Education Scholarship, 10(1), 53-62. https://doi.org/10.1515/ijnes-2012-0034

Rieger, K., Chernomas, W., McMillan, D., Morin, F., \& Demczuk, L. (2016). The effectiveness and experience of arts-based pedagogy among undergraduate nursing students: a comprehensive systematic review protocol. JBI database of systematic reviews and implementation report, 13(2), 101-124. https://doi.org/10.11124/jbisrir-2015-1891 
The Truth and Reconciliation Commission of Canada [TRC]. (2015). Calls to action. Winnipeg, MB http://www.trc.ca/websites/trcinstitution/File/2015/Findings/Calls_to_Action_English2.p df

Townsend, L., Gray, J., \& Forber, J. (2016). New ways of seeing: Nursing students' experiences of a pilot service learning program in Australia. Nurse Education in Practice, 16(1), 6065. https://doi.org/10.1016/j.nepr.2015.08.004

University of Ottawa. (2017). From cultural awareness to cultural competency. Retrieved from https://www.med.uottawa.ca/sim/data/Serv_Culture_e.htm

Vliem, S. (2015). Nursing students' attitudes toward poverty: does experiential learning make a difference? Nurse Educator, 40(6), 308-312. https://doi.org/10.1097/nne.0000000000000168

Ward, T. (2015). Do you hear what I hear? The impact of a Hearing Voices Simulation on affective domain attributes in nursing students. Nursing Education Perspectives, 35(5), 329-331. https://doi.org/10.5480/14-1448

Yang, K., Woomer, G.R., Agbemenu, K., \& Williams, L. (2014). Relate better and judge less: poverty simulation promoting culturally competent care in community health nursing. Nurse education in practice, 14, 680-685. https://doi.org/10.1016/j.nepr.2014.09.001 